\title{
El flamenco y la política de patrimonio en Andalucía. Anotaciones a los registros sonoros de la Niña de los Peines
}

\author{
Cristina Cruces Roldán \\ Profesora Titular de Antropología Social de la \\ Universidad de Sevilla
}

\section{Introducción. \\ El flamenco como patrimonio cultural}

El 3 de Julio de 1999 se publicó en BOJA el Decreto por el que se declaraban Bien de Interés Cultural, con la categoría de Patrimonio Documental, los registros sonoros de la Niña de los Peines radicados en Andalucía. La definitiva publicación en BOE ( I I de Agosto de 1999) culminaba el proceso por el cual, por primera vez, se ejecutaba la política andaluza de Bienes Culturales sobre el flamenco, entendido como Patrimonio Cultural en su expresión más estrictamente administrativa.

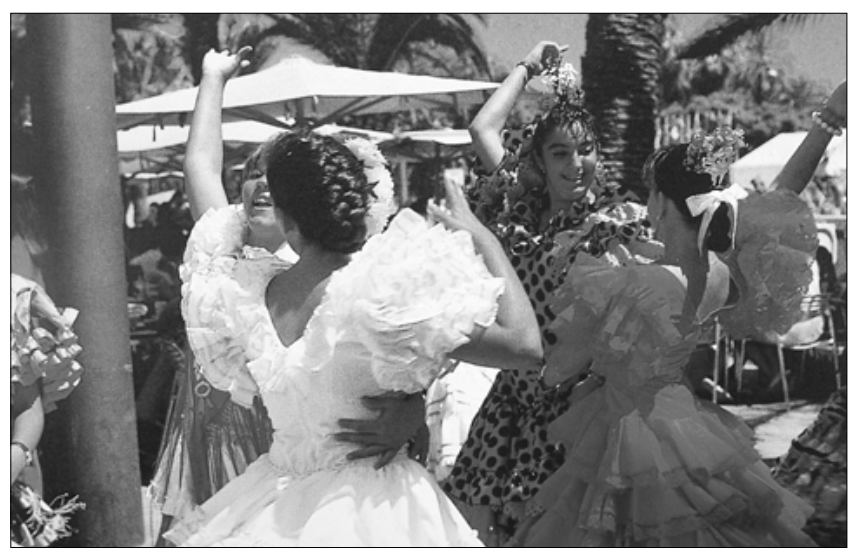

Baile por sevillanas actual

Este artículo es un resumen de algunos de los contenidos del libro, actualmente en prensa, El flamenco como Patrimonio. Anotaciones sobre la Declaración como Bien de Interés Cultural de los Registros Sonoros de la Niña de los Peines.
Este acontecimiento no ha pasado por alto a quienes entendemos que la exclusiva consideración del flamenco como un género artístico supone seccionar una significación cultural de calado mucho más hondo. Máxime cuando es un fenómeno todavía no suficientemente valorado ni por las instituciones ni por la sociedad civil. El flamenco puede parecer incluso "intruso" o sin carta de naturaleza en el campo del Patrimonio Histórico y Cultural, acostumbrado a seguir criterios reduccionistas en sus acciones, tales como la aplicación práctica sobre los bienes residuales, a extinguir, raros, antiguos o preferentemente objetos materiales.
La publicación de la Ley del Patrimonio Histórico de Andalucía (|/|99|) abrió nuevas posibilidades para incorporar al Inventario de Bienes de Interés Etnológico, inscribir en el Catálogo del Patrimonio Histórico de Andalucía o Declarar como Bien de Interés Cultural expresiones culturales cuyo carácter "tradicional" no siempre coincide con la norma dictada en la Ley 96/85 de Patrimonio Histórico Español para los llamados "Materiales Etnográficos" '. La legislación andaluza sobre Patrimonio Etnográfico se basa más bien en la relevancia de estos bienes para la "cultura y modos de vida propios del pueblo andaluz"2, remitiendo antes al concepto "identidad" que a difusos atavismos, y adopta un criterio emergente, en expresión de García Canclini, para los nuevos significados y valores, prácticas y relaciones sociales sobre los que procede.

Diversos agentes han puesto de manifiesto la dificultad de plantear acciones concretas en ciertos apartados de este patrimonio, por varios motivos: el excesivo y poco definido contenido de lo que pueda considerarse "relevante", la urgencia de las decisiones a tomar que impide en ocasiones un diseño racionalizado de estrategias-, $y$, en general, la carencia de medios para llevarlas a cabo. Pero, sobre todo, se hace notar una común inquietud acerca de la complejidad de incorporar al automatismo administrativo elementos patrimoniales que no tienen una plasmación material exacta (acciones, rituales, representaciones simbólicas, significación social...), máxime cuando son considerados a un nivel de "patrimonio modesto" en nada comparable a grandes monumentos, objetos artísticos o raros yacimientos.

La reglamentación del Catálogo del Patrimonio Histórico de Andalucía ${ }^{3}$ y la incorporación de las categorías de Lugar de Interés Etnológico y Actividad de Interés Etnológico ${ }^{4}$, deben entenderse como intentos de operacionalizar la complejidad antedicha. Para el Patrimonio Etnográfico se puede hacer uso, además, de las tipologías de "Monumento" (como los Lugares de Interés Etnológico, dentro del Patrimonio Inmueble) y "Objetos e instrumentos de interés etnográfico" (dentro del Patrimonio Mueble), quedando disponibles las categorías más específicas de Patrimonio Bibliográfico y Documental para otro tipo de bienes. Quiere esto decir que, con la legislación en la mano, los instrumentos disponibles podrían recoger expresiones culturales tan diversas como un molino aceitero, un corral de vecinos, el entorno natural de una romería, el significado de determinada imagen para los procesos de 
identificación local de un pueblo, el asociacionismo de los cuarteles cordobeses de Semana Santa, la doma a la vaquera, los saberes aplicados a la elaboración de botas y zapatos de baile flamenco, o el traje masculino de los cascabeleros de Alosno. Lo determinante, en términos legales, es que todos estos aspectos sean parte de la identidad cultural de Andalucía o alguno de los colectivos que la forman. En principio, para la legislación andaluza, no importa tanto la "tradicionalidad" como la "significación cultural", por lo que valdría incorporar al Catálogo, Inventario o declarar como Bien de Interés Cultural manifestaciones actualizadas en las que no están presentes ni subjetivos criterios estéticos, ni límites preestablecidos de antigüedad, escasez, rareza o monumentalidad: formas de sociabilidad de los jóvenes urbanos andaluces, la feria de noche de Almería, el modelo educativo de la familia... siempre y cuando tengan sentido identitario.

Algo de todo esto es plenamente aplicable al flamenco. El flamenco es un género artístico y una práctica popular, "tradicional" si lo entendemos como parte de la historia y la herencia del pasado (pasado reciente, en cualquier caso, pues no tiene más de dos siglos de existencia) y de la construcción de Andalucía como pueblo diferenciado. Pero también es una práctica viva, plenamente funcional, y de ahí su persistencia y centralidad para la cultura andaluza. Cierto es que, mientras la vivacidad de su manifestación formal como espectáculo es creciente, su pujanza en el campo de la práctica popular cotidiana atraviesa por una generalizada desaceleración, y en algunos casos desaparición definitiva. Un hecho que tiene que ver con la propia transformación de los espacios y los ritmos de vida ordinarios que han servido a la convivencia en Andalucía y con la incorporación de claves estéticas ajenas. Y más aún: el flamenco ha sufrido desde siempre procesos de apropiación, gestión e interpretación extraños a sus protagonistas y contrarios muchas veces a los intereses de Andalucía como pueblo, desde la imagen distorsionada de los viajeros románticos hasta su más reciente confusión en el repertorio discográfico de las "músicas étnicas" sobre la espuria categoría del "nuevo flamenco", pasando por su despreciativa inclusión en la "españolada" noventayochista y su estatalización durante la Dictadura franquista. Los intereses políticos han decidido en cada momento la construcción de una "imagen del flamenco", qué aspectos debían o no fomentarse, cuándo hacer uso de él en los discursos sobre la construcción identitaria de Andalucía. La industria artística, por su parte, se ha encargado de redefinir e instrumentalizar el contenido del flamenco fetichizando su sentido particularizadamente andaluz en favor de una generalización que descarga de contenidos étnicos y de clase el modelo expresivo al que refiere.

Pocas veces se ha atendido, empero, a una reflexión que defina al flamenco de forma integradora como parte del Patrimonio Cultural. El flamenco es un fenómeno que adquiere múltiples formas de manifestación, es plurifuncional y polisémico. Lo que resultaría realmente eficaz con los instrumentos que nos ofrece la legislación vigente sobre Patrimonio, sería no excluir ningún aspecto para su definición, sino considerarlo una expresión sociocultural completa, y tal vez ahora sea el momento definitivo para hacerlo. Contamos con un inconveniente: una definición holística del flamenco tiende a enmarañar más que facilitar, en principio, cualquier acercamiento al modelo de categorías del Patrimonio Inmueble, Mueble, Etnográfico, Bibliográfico y Documental impuesto por la Ley I/91 y su posterior desarrollo en el RD 19/1995 para la actuación sobre los bienes culturales. Pensemos que en el flamenco se combinan aspectos de muy diferente naturaleza: se entiende por "flamenco" tanto el género artístico como los bienes materiales, la producción músico-oral, los espacios y entornos flamencos, rituales, agrupamientos, procesos de transmisión de saberes característicamente flamencos, y hay hasta quien menciona que el flamenco es un verdadero "modo de vida", confiriéndole un valor de trascendencia respecto al propio arte. Por otro lado, dos cuestiones -enriquecedoras respecto a sus contenidos- hacen imprecisa la barrera de la protección: una, el flamenco se encuentra en continua recreación y reinterpretación a partir de una estructura básica, compartida en lo fundamental; otra, en él participan la práctica popular, no enajenable, y la industria del espectáculo, cada una con sus propias claves de producción y reproducción, no siempre coincidentes.

La estructura administrativa de la Consejería de Cultura de la Junta de Andalucía permite la confluencia de
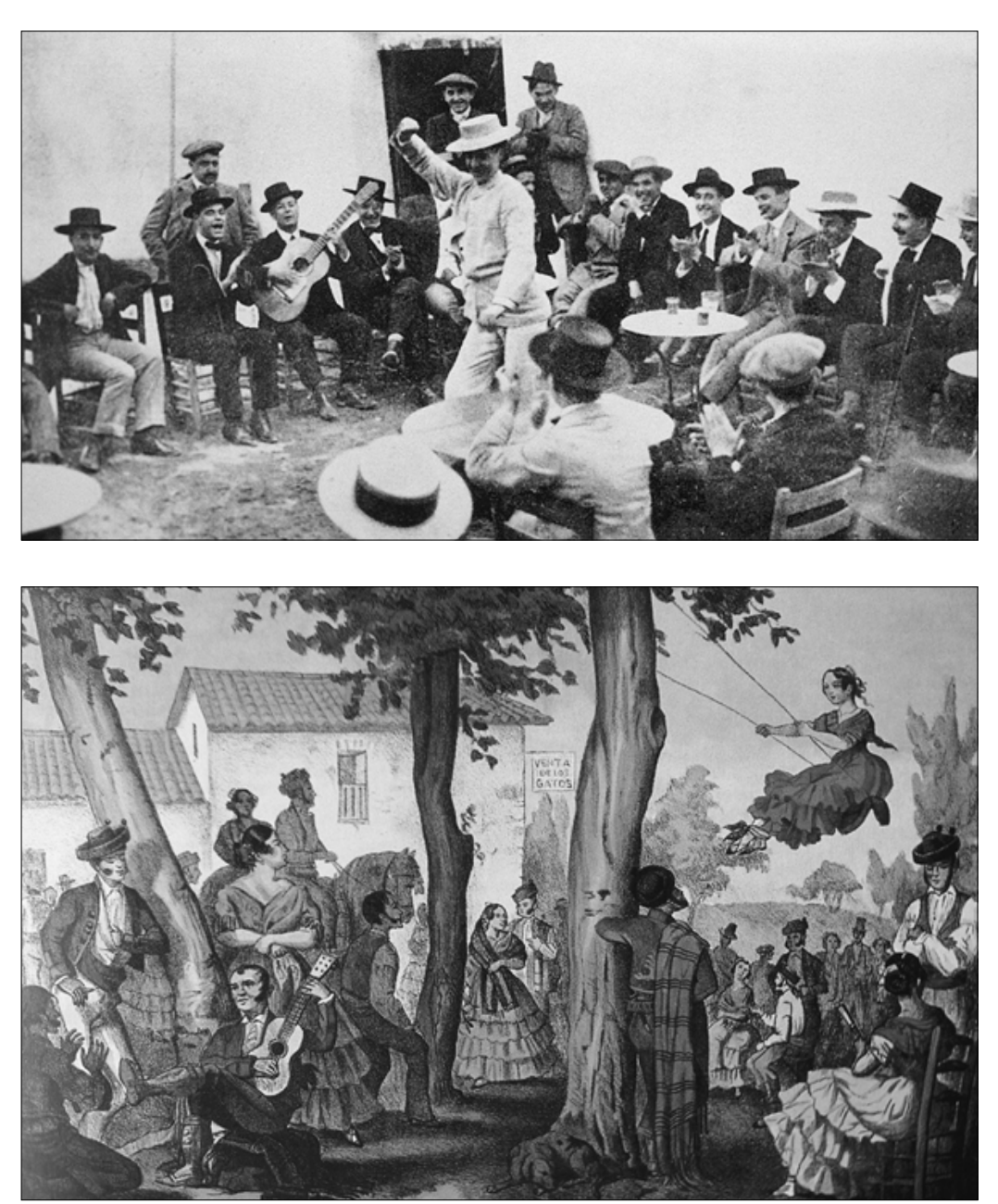

Fiesta flamenca en Sevilla (años 10). Dos modelos de ritualización flamenca

Entorno campestre para una ocasión flamenca tradicional: el columpio 


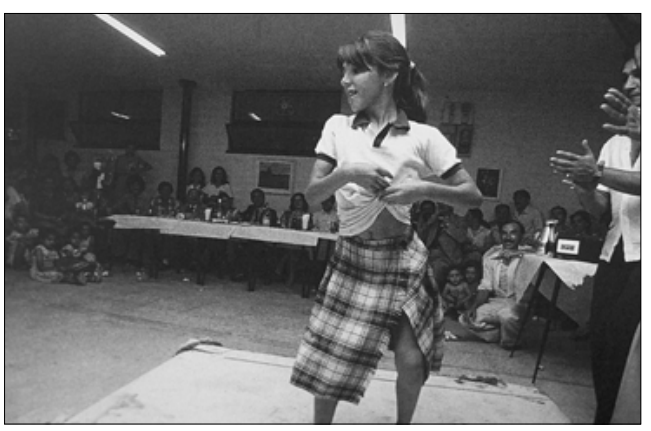

Baile flamenco espontáneo
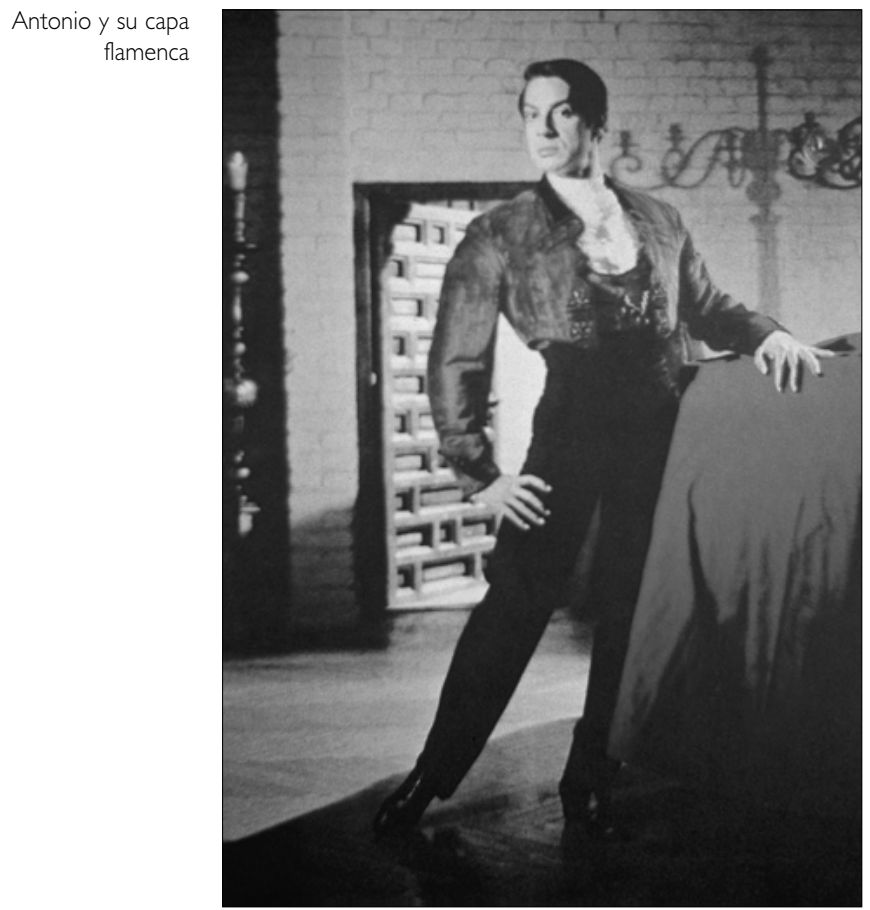

estos dos aspectos, que la razón aconseja separar por lo que refiere a políticas de intervención: la documentación, catalogación, protección, conservación y difusión del flamenco, vinculadas a la idea de "Patrimonio Cultural", compete a las Direcciones Generales de Bienes Culturales e Instituciones del Patrimonio; y la dimensión artística y expresiva, que corresponde a la tutela de Fomento y Promoción Cultural.

Nos centraremos en la dimensión patrimonial del flamenco ${ }^{5}$, aplicándole el mismo sentido totalizador y omnicomprensivo que detenta el concepto antropológico de "Cultura". Se puede facilitar la mecánica administrativa a través de una primera operacionalización metodológica, que agrupe los contenidos del flamenco en apartados:

a) Patrimonio material flamenco, para el que podrían aplicarse las categorías de Bienes Muebles del Patrimonio Etnográfico, Patrimonio Bibliográfico y Patrimonio Documental, y donde se incluyen:

- El catálogo de los recursos materiales más directamente vinculados a la ejecución del arte flamenco, de anónimos o documentados propietarios: instrumentos musicales (según estilo y época histórica: guitarra, palillos, crótalos, panderos, vihuelas, violines, botellas, castañuelas, zambombas, cántaros, cajón...); indumentaria de uso para la práctica del flamenco (zapatería especializada, batas de cola, mantones, calzonas de baile...), aderezos y adornos (caireles, pendientes de coral, peinetas...). Para una acertada aplicación administrativa, los aspectos formales deben acompañarse de variables como uso, funcionalidad, contexto de aparición, transformaciones históricas, técnicas de construcción o elaboración, etc. Una capa que haya pertenecido a Antonio Ruiz Soler, por ejemplo, se incluiría en este apartado basándose más que en el valor material, el tejido o la elaboración del objeto, en su pertenencia a una figura indiscutible del flamenco, su relevancia para la difusión del baile de la caña, la reinterpretación de la capa española desde la mera indumentaria al género artístico, las posibilidades técnicas que ofrece en la danza flamenca masculina (vuelo, color, utilización del espacio...), la adaptación del modelo interpretativo a los condicionantes impuestos por la capa (equilibrio, peso, ocupación de las manos...), etc.

- Los registros sonoros y audio-visuales del flamenco, acogiendo aquellos en desuso que suelen formar parte de colecciones privadas (cilindros de cera, discos monofaciales, placas de 78 r.p.m.) pero también la producción discográfica más reciente en soportes que, en muchos casos, están descatalogados (discos de vinilo). Igualmente, la escasa producción audiovisual flamenca (desde la producción fímica de principios de siglo hasta la actual, pasando por el cine flamenquista y los registros de grabaciones privadas) debería ser, al menos, documentada, catalogada y, si existe riesgo de conservación, protegida.

- La documentación gráfica: colecciones fotográficas, compendios hemerográficos, cartelería y folletos, cancioneros, e incluso ciertas obras bibliográficas de especial relevancia, sobre las que se debe actuar en los términos antedichos. Conviene señalar los riesgos derivados de la dispersión, sobre todo del material gráfico, que incita con más motivo a tratar de cubrir, al menos, la documentación de lo disponible.

b) Expresiones músico-orales y plásticas del flamenco (Actividades de Interés Etnológico), aspecto que indiscutiblemente ha captado más atención hasta el momento por identificarlo como el núcleo del "arte flamenco" y diseccionarlo así, de modo reduccionista, con el flamenco mismo.

- En lo literario-oral, destacamos el compendio etnohistórico que representan las coplas flamencas para el conocimiento de la vida cotidiana de las clases populares andaluzas, sus valoraciones, simbolismos y prácticas, como una especie de anales a partir de los cuales se puede reescribir la historia de las "gentes sin historia". Aquí cabe la selección del conjunto del acervo letrístico popular flamenco, en sus aspectos temáticos, morfológicos, por palos o estilos... con el objetivo de construir una base de datos definitiva de este material. 
- En lo musical, el flamenco es un producto especialísimo localizado dentro de la tradición de las músicas orientales. Su particularidad reside en la utilización privativa de la cadencia andaluza, el microtonalismo y los recursos melismáticos comacromáticos, las armonías entre lo modal y lo tonal, el ornamentismo, la polirritmia, y la fuerza del factor emocional en su ejecución. Forman parte del patrimonio musical flamenco el cante, el baile y el toque de guitarra y de todos aquellos utensilios de acompañamiento propios de formas musicales (crótalos, chinchillas y violines en los verdiales, zambombas, botellas, alpargatas y cántaros en los villancicos...) y otros -e incluso estos mismosincorporados más recientemente a las piezas flamencas contemporáneas (cajón, pandero...). Asimismo, forman parte de este patrimonio musical la percusión corporal (pitos, palmas sordas y sonoras, simples y "redoblás", zapateado, golpes en pecho y piernas) que, con frecuencia, se confunde dentro del amplio apartado de los "jaleos", compuesto también por los jaleos verbales e interjecciones flamencas. Respecto al baile, todas las formas interpretativas que recogen los ricos sincretismos de las escuelas de danza orientales, las danzas moriscas, gitanas, bailes folklóricos pre o para-flamencos, escuela bolera, bailes de palillos, danza contemporánea y, naturalmente, creaciones artísticas personales.

Para una mejor sistematización del patrimonio músico-oral y plástico del flamenco, estas expresiones se pueden clasificar en tres apartados:

- Técnicas de ejecución de baile, toque o cante: En el baile, el zapateado, desplantes, cierres, llamadas, escobillas, ondulación, torsión, vaivenes, pateo, braceo, oposiciones, giros de muñeca, quiebros...; en la guitarra, rasgueos, arpegios, punteos y picados, trémolos, alzapúa, transportes; en el cante, ornamentismo, uso de sonidos palatales, nasales y guturales, vibratos, glosolalias, disonancia, paronomasia, trabalenguas, gorjeos, quiebros, trinos, floreos, melismas, impostación, filado, apoyaturas, síncopas, transportes, fraseos,... Incluimos aquí las especificidades musicales del flamenco que lo distinguen de otras músicas: acordes, cadencias, modelos melódicos, esquemas rítmicos, etc.

- Unidades expresivas, es decir, los tipos de baile, toque o cante también llamados palos o estilos, como "rondeñas", "fandangos", "bulerías", "soleá",... toda la diversidad interna del flamenco, exhaustivamente recogida y teniendo en cuenta las peculiaridades que los caracterizan: en el baile, baile individual o grupal; de ejecución espontánea o académica; de pequeño, mediano o gran formato; en el toque, si es de acompañamiento o de concierto; en el cante, si se trata de cantes a compás o ad libitum...

- Piezas singulares, codificadas y que podemos calificar "de autor": coreografía de "El Amor Brujo" de La Argentina; Rondeña de Ramón Montoya; Canasteras de Camarón; "Entre dos aguas" de Paco de Lucía; "Soleá del Mantón" de Blanca del Rey... c) Espacios, prácticas y rituales de expresión flamenca, según las tipologías de Monumentos y Lugares y la categoría de Actividades de Interés Etnológico. Metodológicamente, cabe clasificar las prácticas flamencas según el nivel de institucionalización y formalización, el grado de participación y los vínculos entre las partes que las integran y la distinción entre lo que denominaremos el valor de uso de la expresión flamenca, y su valor de cambio, una vez que ésta se convierte en mercancía. Respecto a rituales y prácticas "de uso", el flamenco se desarrolla en fiestas con ocasión de ritos de paso (bautizos, bodas, y hasta comuniones y cumpleaños), lugares de sociabilidad informal (tabernas, tabancos, ventas, plazas, cuartos de cabales, vecindades, patios de vecinos, puertas de las casas), acontecimientos festivos (ferias, romerías, carnavales), ámbitos laborales (gañanías, cortijos, minas, fraguas) y todo lo que representa el hábito de "cantar" como costumbre en la vida cotidiana de los andaluces. En lo segundo, el flamenco comercial, determinadas formas de representación pueden ser acogidas en el campo patrimonial por su trayectoria histórica (algunos tablaos, festivales flamencos), por su singularidad (Bienal de Flamenco, Festival de Música y Danza de Granada, Concurso de Córdoba) o por su contenido societario (recitales en las peñas flamencas, ciertos espectáculos locales).

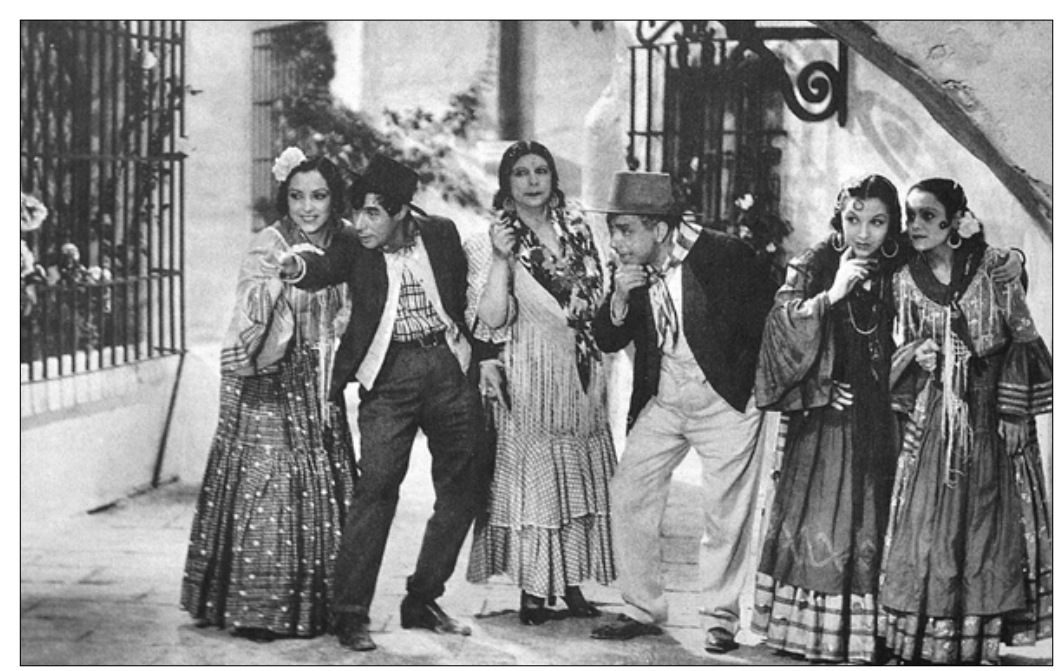

Cine flamenquista -"La Marquesona"-

Metodológicamente, cabe utilizar sistematizaciones con Pastora Imperio de tipo descriptivo, correlacional o interpretativo. Descriptivamente, se puede documentar el modo en el que se diseña y experimenta un ritual flamenco según variables como los actores (diversidad étnica, de clase, de género, socio-profesional, etárea), la intencionalidad (si se trata de una fiesta cíclica, espontánea, de objetivo religioso, de ciclo vital...), dimensiones espacio-temporales (secuencia y localización de hechos), materiales (adornos, instrumentos, comida y bebida...), formación e interrelación de grupos, niveles de participación y división del trabajo, etc. Se puede pasar a la correlación de los datos recogiendo aspectos tales como el modo en que la variable "etnicidad" se relaciona con la estética, el género con la participación o la edad con la división del trabajo... Un acercamiento rayano ya en el nivel interpretativo: 


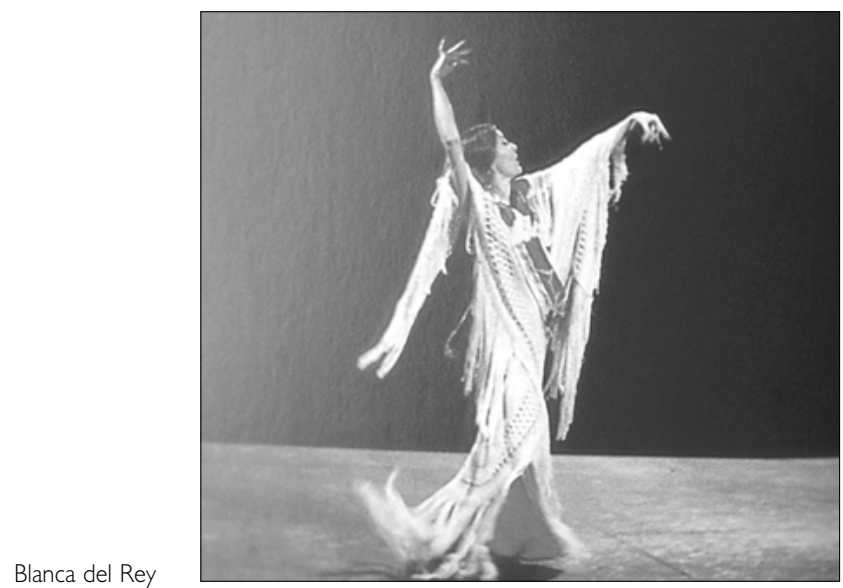

en la catalogación cabe introducir el análisis de la significación funcional, explicar el proceso ritual, las situaciones de interrelación social basándose en modelos de segmentación, etc.

d) Saberes y significaciones culturales (Actividades de Interés Etnológico). El flamenco es fruto de experiencias y trayectorias comunes de sectores sociales concretos del pueblo andaluz. Por tanto, es también un cuerpo de saberes y significados compartidos colectivamente significativos. Al anotar este epígrafe, pretendemos introducir gran parte del patrimonio inmaterial que tiene que ver con las ideas de experiencia y significación. Poco se ha dicho de esto en la investigación al uso: son cuestiones que resultan de difícil acercamiento, incluso si de su puesta en práctica se deriva una plasmación material clara, como es el caso de los saberes aplicados a la construcción de guitarras, que quedan reflejados en los instrumentos mismos. Pero múltiples perspectivas temáticas de este signo demandan ya un acercamiento científico: flamenco como representación ritual que utiliza símbolos y tiene significados propios; cuerpo de saberes y conocimientos del flamenco, formas de transmisión y procesos de aprendizaje de los mismos; oralidad flamenca: vocabularios, giros, expresiones...; análisis de la gestualidad y corporeidad flamencas; el flamenco como oficio y las culturas del trabajo de los flamencos; culturas étnicas y culturas de género en el flamenco; trascendencia de la significación a la acción social ("ser flamenco")...

Algunos de los epígrafes clasificatorios que nos hemos atrevido a sugerir son de cómoda y diáfana aprehensión empírica; otros, a lo sumo, referentes de cierta evidencia sensorial. En algún caso son aspectos manifiestamente intangibles y cuya existencia real no está objetivada para facilitar el acercamiento administrativo. Pero ninguno de estos elementos tiene existencia independiente: su valor cultural es una construcción histórica de interdependencias mutuas entre los objetos, las acciones de los grupos sociales y el significado e interpretación que tales grupos otorgan a objetos y acciones. Sólo desde esta perspectiva del flamenco como complejo cultural, tiene sentido acometer la tarea de convertirlo en objeto de políticas de patrimonio efectivas.

\section{Instrumentos legales y administrativos}

Por su significación social de carácter popular y por las diversas dimensiones material, ritual y simbólica que lo dotan de sentido identitario, entendemos que el flamenco debe ser tratado en las políticas de Patrimonio de forma preferente. Sólo así se podrá realizar el oportuno ejercicio de valoración desde la propia Andalucía, frente a la corrección política imperante según la cual cualquier expresión cultural que se precie debe calificarse como "patrimonio universal"6. En la Ley de Patrimonio Histórico de Andalucía de 1991, los diferentes aspectos de definición del flamenco como "Patrimonio Cultural" que hemos visto antes pueden quedar servidos con las categorías legislativas vigentes, tanto en el Patrimonio Inmueble como en Mueble, Bibliográfico, Documental y el Patrimonio Etnográfico (Título VII), donde se incluyen "lugares, bienes y actividades que alberguen o constituyan formas relevantes de expresión de la cultura y modos de vida propios del pueblo andaluz"7. Se debe hacer notar, en este sentido, que las categorías más complejas desarrolladas en el Catálogo son, precisamente, aquellas en que aparece la palabra "Etnología" (Lugares y Actividades de Interés Etnológico), al introducir elementos que van más allá de lo material o lo histórico y cuya documentación resulta más novedosa y arriesgada.

Tres son las actuaciones posibles sobre los bienes culturales flamencos: la inclusión en el Inventario de Bienes de Interés Etnológico, que tiene por objeto recoger bienes no declarados de Interés Cultural pero que tengan "singular relevancia"; la inscripción en el Catálogo del Patrimonio Histórico de Andalucía, genérica si se trata de poner el énfasis en la significación cultural y la protección contra los riesgos de su posible desaparición, y específica para detallar la actuación en favor de un bien cultural particular; y la figura de más peso en la protección: la de Bien de Interés Cultural. En el cuadro de la siguiente página recogemos un resumen de las categorías posibles, según la Ley I/91, el Catálogo, $y$, de forma comparativa, la Ley estatal.

Nos vamos a centrar en el estudio de la Documentación Técnica elaborada para la inclusión en el Catálogo de Lugares y Actividades de Interés Etnológico, por tratarse de dos categorías que abren expectativas novedosas. La primera permite vincular al flamenco con todos aquellos espacios relacionados con los procesos de trabajo y donde se produce la sociabilidad colectiva. Aquí quedarían incluidos bares, peñas, lonjas, mercados, lugares de manifestación ritual cotidiana y festivo-ceremonial (parajes de romerías, ferias, etc.). Pueden recogerse las construcciones o instalaciones que albergan actividades relacionadas con el flamenco, además de los objetos muebles asociados. Lo mismo sucede para las Actividades de Interés Etnológico, prácticas y conocimientos que constituyen expresiones significativas del flamenco y categoría que no sólo sirve para documentar y, en su caso, proteger, sino también para la aceptación de estas actividades por parte de sus protagonistas, de tal forma que los propios actores sociales sean los naturales depositarios de su conservación. 
El esquema de trabajo sistematizado en el Catálogo recoge 17 niveles de información útiles sobre todo para el caso de que el bien objeto de inscripción esté clara y limitadamente definido $"$. Si se toma el flamenco desde una perspectiva globalizadora, difícilmente se puede inscribir como fenómeno amplio y holístico con los niveles de información disponibles, y resulta complicada la incorporación directa de algunos datos en los epígrafes propuestos incluso si elementos fragmentarios de las mismas son tomados en consideración.

Analicemos pues algunos de estos epígrafes desarrollados en la Documentación Técnica, en función de su eficacia para este tipo de patrimonio:

I. En la localización, el principal problema que puede surgir para el flamenco acontece por la falta de claridad en la localización de algunos de sus procesos, o porque su dispersión es tal que se dificulta el procedimiento de inscripción. El baile por verdiales, por ejemplo, se puede dar en las reuniones festivas de los Montes, de Vélez o Coín, en las Academias de Málaga, en un ritual privado de boda, una peña flamenca, una fiesta local; de forma profesionalizada o no, etc. Posiblemente, la mejor solución para documentar estos procesos sería seleccionar una parte de esta delimitación (p.e. catalogar el baile por verdiales de los Montes) o bien realizar tipologías delimitativas diferentes e identificarlas de forma exacta para estos casos (p.e. espacio de fiestas comarcales, locales de enseñanza, espacios privados etc.) 12. Lo mismo sucede con ciertas actividades aso- ciadas al flamenco no tienen un soporte material claro que permita una diáfana localización o plasmación espacial exacta; más bien, se incorporan al difuso campo de los saberes, la transmisión cultural, etc., como sucede a los procedimientos domésticos o académicos de aprendizaje de baile, cante o toque.

2. En relación con el epígrafe de tipología o clasificación, se deben decidir criterios exhaustivos, exclusivos y precisos: si se tratará de una clasificación formal, temporal, funcional, material, relacional... Cualquier práctica puede plantearse en forma multidimensional: si consideramos la ejecución de un fandango por parte de un cantaor junto a un guitarrista en una reunión privada de una romería, como representación de una actividad flamenca, esta situación podría clasificarse según el estilo cantado, el momento en que se produce, la funcionalidad que lo caracteriza (festiva, privada, "no mercantil"), el tipo de atuendo, el modelo de sociabilidad en que se produce, o introducir un elemento de clasificación que refiera a campo de lo simbólico, de las valoraciones y creencias que no tienen plasmación material o relacional inmediata.

3. La incorporación de un nivel informativo de justificación es ocasión idónea para insistir aún más en la substancialidad del flamenco como representación identitaria para Andalucía, y hacerlo vehementemente con el objetivo de contrarrestar en lo posible el carácter

\begin{tabular}{|c|c|c|}
\hline $\begin{array}{l}\text { Categoría de } \\
\text { clasificación } \\
\text { (Ley 1/91) }\end{array}$ & $\begin{array}{l}\text { Catálogo del Patrimonio Histórico } \\
\text { de Andalucía, } 1995^{8} \\
\text { - Inscripción Genérica } \\
\text { - Inscripción Específica } \\
\text { - Bienes de Interés Cultural9 }\end{array}$ & $\begin{array}{l}\text { Reglamento de Desarrollo } \\
\text { D. 111/1986 (Ley de P. H. Español) } \\
\text { - Bien de Interés Cultural } \\
\text { - Inventario General }\end{array}$ \\
\hline Patrimonio Inmueble & $\begin{array}{l}\text { - Monumentos } \\
\text { - Lugares de Interés Etnológico* }\end{array}$ & $\begin{array}{l}\text { - No incluye la categoría } \\
\text { "Lugar de Interés Etnológico" }\end{array}$ \\
\hline Patrimonio Mueble & $\begin{array}{l}\text { - Objetos e instrumentos de } \\
\text { Interés Etnográfico* }\end{array}$ & $\begin{array}{l}\text { - Separado en la categoría de } \\
\text { "Materiales Etnográficos" }\end{array}$ \\
\hline Patrimonio Etnográfico & $\begin{array}{l}\text { - Actividades de Interés } \\
\text { Etnológico }\end{array}$ & $\begin{array}{l}\text { - No aparece como "Patrimonio } \\
\text { Etnográfico" sino como } \\
\text { "Materiales Etnográficos" }\end{array}$ \\
\hline Patrimonio Documental & $\begin{array}{l}\text { - Documentos } \\
\text { - Archivos }\end{array}$ & $\begin{array}{l}\text { - Diferencia entre Manuscritos, } \\
\text { Impresos y Colecciones }\end{array}$ \\
\hline Patrimonio Bibliográfico & $\begin{array}{l}\text { - Libros } \\
\text { - Bibliotecas }\end{array}$ & $\begin{array}{l}\text { - Diferencia entre Manuscritos, } \\
\text { Impresos y Colecciones }\end{array}$ \\
\hline
\end{tabular}

\footnotetext{
* Entre otras categorías
}

Fuente: Elaboración propia a partir de las fuentes legales 

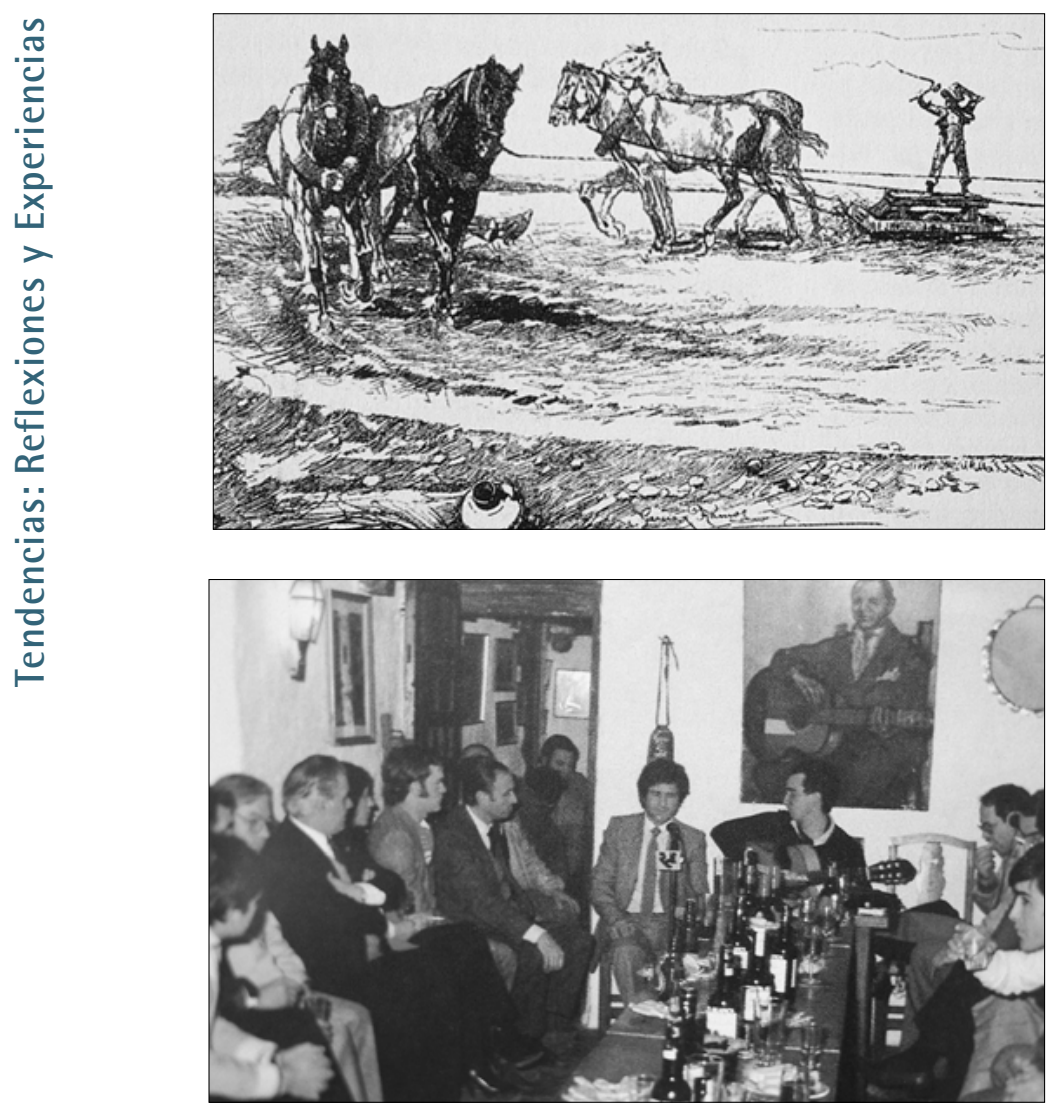

Faena de la trilla, base del cante del mismo nombre

Peña Juan Breva, Málaga social e intelectualmente desvalorado que se ha otorgado tradicionalmente a materiales y prácticas no contemplados dentro del patrimonio "culto", cuya centralidad radica precisamente en formar parte de los modos de vida cotidianos. Es el momento también de amparar estos modos de vida en el contexto urbanístico en el que se producen ${ }^{13}$, poniendo atención a los discursos que, bajo intereses especulativos, esconden una supuesta defensa del bienestar que se opondría a un discurso patrimonial básicamente arcaicista sobre algunos barrios de pueblos y ciudades andaluces caracterizados por su práctica flamenca. El profesional debe documentar, difundiendo, perspectivas conservacionistas si así se requiere, y siempre que sean razonadas y justificadas convenientemente.

4. En relación con la justificación del bien se encuentra el punto sobre la descripción del mismo. En el caso del Patrimonio Inmueble, el art. 86 del Reglamento de Protección y Fomento indica que no sólo se deben conservar los bienes sino también los valores etnológicos inherentes a ellos. Sorprende observar, en cambio, que en la descripción propuesta en la Documentación Técnica no aparecen estos elementos. El Lugar de Interés Etnológico se subordina a una repetida consideración arquitectónica del bien, todo lo más distinguiendo entre elementos estructurales y no estructurales, exteriores o interiores... $\mathrm{Ni}$ siquiera aparece el apartado de "usos" que sí se incluía en el Decreto | | ///986 de la ley estatal y que, en el caso del flamenco, podría incorporar parámetros como relaciones de sociabilidad, valores simbóli- cos o prácticas rituales, en relación con otra información cruzada, tal que la antigüedad de estas prácticas, el peso específico en su entorno, la reproducción de formas de vida, etc.

Este punto resulta especialmente delicado para la documentación de expresiones culturales flamencas que toman cuerpo en entornos que no habría que conservar por su valor en sí mismos, sino como la memoria de lo que contribuyeron a crear o la funcionalidad de lo que aún son capaces de albergar. Los lugares pueden tener valor desde el punto de vista económico (un determinado negocio de consumo de estirpe flamenca, como ciertas "tiendas de montañeses" en Cádiz), social (corrales de vecinos) o simbólico (caminos del Rocío). Pero existen dudas más que razonables acerca de la conversión de ciertos espacios donde hoy toma cuerpo el "flamenco de uso", en objeto de interés patrimonial, incluso si su significación social es clara. Los valores a preservar se producen muchas veces a pesar de su incorporación a un determinado ámbito residencial o de convivencia más que gracias a él, y gran parte del patrimonio flamenco "vivo" hay que buscarlo hoy, no en entornos atávicos más o menos inventados, sino precisamente en entornos urbanísticos que pueden ser ejemplo de un mal concepto de la habitación, como ciertos polígonos y barriadas de bloques de pisos construidos en los años 60 y 70 en los alrededores de los núcleos urbanos. ¿Cabe aquí la preservación?.

El apartado más complejo dentro del epígrafe de "descripción" corresponde a las Actividades de Interés Etnológico. El contenido de la Documentación Técnica está poco desarrollado, limitándose a "fases" o "procesos", "secuencia temporal" y "agentes". Parámetros válidos para completar la información de las Actividades de Interés Etnológico podrían ser:

- Tipo o categoría de la actividad: saberes (conocimiento y transmisión de los diversos estilos de soleá), técnica (procedimientos de ejecución del baile por rondeña), sociabilidad (puesta en escena festivoceremonial de la Fiesta de la Bulería de Jerez)...

- Secuencia espacial: localización concreta (técnicas de toque que se dan en una determinada localidad) / dispersa (conjunto de formas de toque de castañuelas utilizadas en el baile femenino); ámbitos de representación (rural-urbana; vecinal-familiar)...

- Secuencia temporal: ciclos (reunión anual de zambombas navideñas), fases (preparación, reunión, participación, consumo, posible repetición diaria-semanal de la fiesta), regularidad/irregularidad...

- Procesos de transmisión (reglada en academias, mimetismo discográfico, creatividad personal, intervención en rituales...)

- Usos y funcionalidad (manifiesta: festividad religiosa / latente: sociabilidad, proyección social, refrendo o adquisición de estatus...) 
- Aspectos económicos, sociales y simbólicos asociados (prestaciones de servicios, contratos artísticos, formación de grupos, procesos de identificación local, étnica, de género, de clase...)

- Origen, evolución y situación actual (desarrollo del toque por sevillanas, análisis comparativo por épocas...)

5. Respecto a los bienes vinculados al inmueble o la actividad o la actividad, la ficha elaborada en la Documentación Técnica interesa por el reconocimiento que hace del carácter inseparable de los mismos y su justificación física, funcional o histórica, así como por su completa elaboración ${ }^{14}$. La descripción se ajusta sin embargo al carácter singular e independiente de los bienes, sin contemplar explícitamente la funcionalidad que estos objetos tienen. Para considerar Lugar de Interés Etnológico la Peña "La Platería", de Granada, habría que realizar no sólo la documentación del inmueble -en sí ya especialísimo, al tratarse de un hermoso carmen granadino- sino de todos los objetos que contiene y presentan relevancia para el inmueble como patrimonio flamenco de esta entidad social: cartelería, archivo discográfico, fotografía, azulejería, objetos decorativos... en razón del uso que de ellos se ha hecho, el procedimiento por el que se han conseguido, su singularidad, su relevancia en la construcción societaria de la peña, etc.

En el caso de los Bienes Muebles adscritos a Actividades de Interés Etnológico, la aplicación de esta ficha resulta algo más compleja. Una actividad vigente supone un proceso vivo, con lo que gran parte de los bienes materiales que se utilizan para su ejecución sufren procesos de evolución y transformación que impiden la disección de modelos únicos. En el caso del baile flamenco y su indumentaria, por ejemplo, existe una imagen de la danza flamenca que se asocia a la bata de cola y la decoración colorista para las mujeres y la calzona pierniceñida y chaquetilla oscura para el hombre.. Pero lo cierto es que los trajes femenino y masculino han atravesado por muchas y variadas plantillas: desde el femenino traje bolero o el "colín" del café cantante a la bata suelta y liviana de crep de los escenarios actuales; desde el masculino casticismo del XIX hasta la camisa negra de seda, el pantalón pinzado de vestir e incluso el semidesnudo de algún artista actual. ¿Dónde situar la raya de los bienes asociados a esta actividad? ¿O habría que concluir aceptando que proponer límites es metodológicamente inadecuado?

Otro desajuste se produce a la hora de documentar bienes muebles adscritos a prácticas dispersas que se producen en tiempos diferentes y por distintos agentes, por lo que la posibilidad de ofrecer datos histórico artísticos, ubicación, estado de conservación o documentación gráfica, tal como se expone en la Documentación Técnica, es muy compleja. El criterio general podría aplicarse a Actividades de Interés Etnológico muy definidas y espacialmente localizadas, unitarias y singulares, como sería el caso de las artesanías de elaboración de guitarras de determinados talleres, donde el instrumental, el depósito de materiales, planos, diseños, y hasta los propios artesanos tienen un recinto concreto en el que ejercen esta actividad. Sin embargo, en otros casos no existen sino grupos de bienes recurrentes que suelen acompañar a la actividad, pero que no tienen carácter singular. En las zambombas navideñas de Arcos de la Frontera itienen interés los lugares que las albergan, los patios o naves en las vecindades implicadas en la fiesta? ¿O, mejor, los instrumentos que suelen emplearse en estas celebraciones, como las panderetas, zambombas, botellas, alpargatas y cántaros? ¿Serán quizá los dulces o comidas que se sirven con ocasión de las fiestas de Pascua? Ninguno de estos objetos tiene carácter singular, pero son afectos a la actividad e indispensables para su puesta en práctica, si bien las zambombas son concebidas de forma distinta en cada sitio. Lo importante, posiblemente, es que hay ciertos elementos comunes, y ésos son los que hay que buscar y catalogar como parte de la actividad. Retomando una idea anterior, es interesante elaborar tipologías-base de Bienes Muebles a los que, ordinaria y generalmente, afecta la actividad documentada, pero sin ese sentido particularizador e inseparable que se confiere al Patrimonio en general. Al mismo tiempo, sería deseable un nuevo campo de información, no recogido en la Documentación Técnica, que exponga la evolución y transformaciones del bien mueble, donde se dé cuenta de los cambios vividos, introduciendo así un matiz diacrónico y procesual.
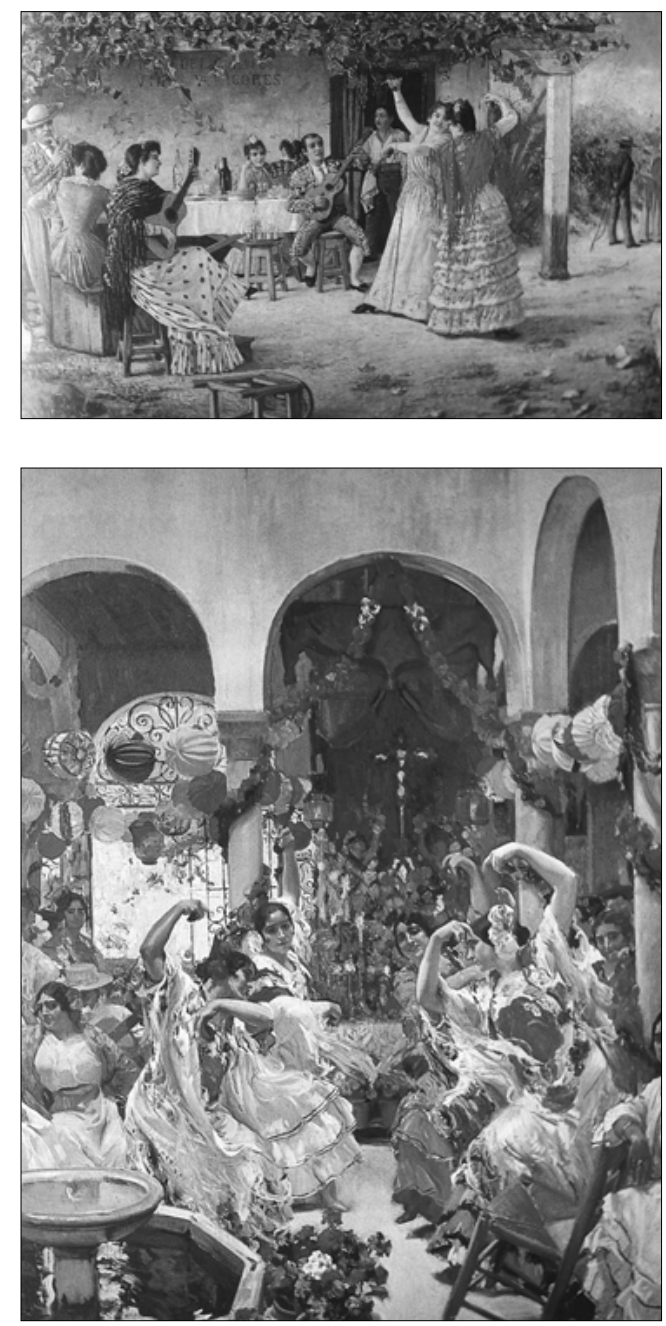

Dos entornos de sociabilidad flamenca rural y urbana tradicionales: ventas y patios de vecindad 
6. Resulta más que discutible la incorporación de un apartado de datos histórico-artísticosdatos, "estilos" o "autores", en espacios y lugares asociados al flamenco que radican en parajes naturales -caso de ciertas romerías o fiestas- o en construcciones que tal vez no tengan demasiado interés desde un punto de vista estético o técnico. Una taberna, por ejemplo, alguna determinada casa de vecindad, el barrio de Santiago de Jerez,... lugares que bien podrían tildarse de Interés Etnológico desde el punto de vista flamenco, pueden tener bastante poco que ver con una idea de "arte culto" que contrasta con el modelo de arquitectura popular que les caracteriza. Nos parece mucho más interesante que la Ley |/ |99| otorgue importancia a delimitar "los elementos tipológicos básicos de la construcción, y la estructura o morfología urbana que deben ser objeto de potenciación o conservación" (art. 30 y ss.). El desarrollo del Reglamento, en este sentido, supone una advertencia muy adecuada para la consideración de los inmuebles como formas de concebir el espacio, definidas socialmente. Esa definición social es una de las pocas tablas de salvación que restan al "flamenco de uso" en Andalucía, que se facilita precisamente por la existencia de tramas espaciales donde se hace favorable el rito.

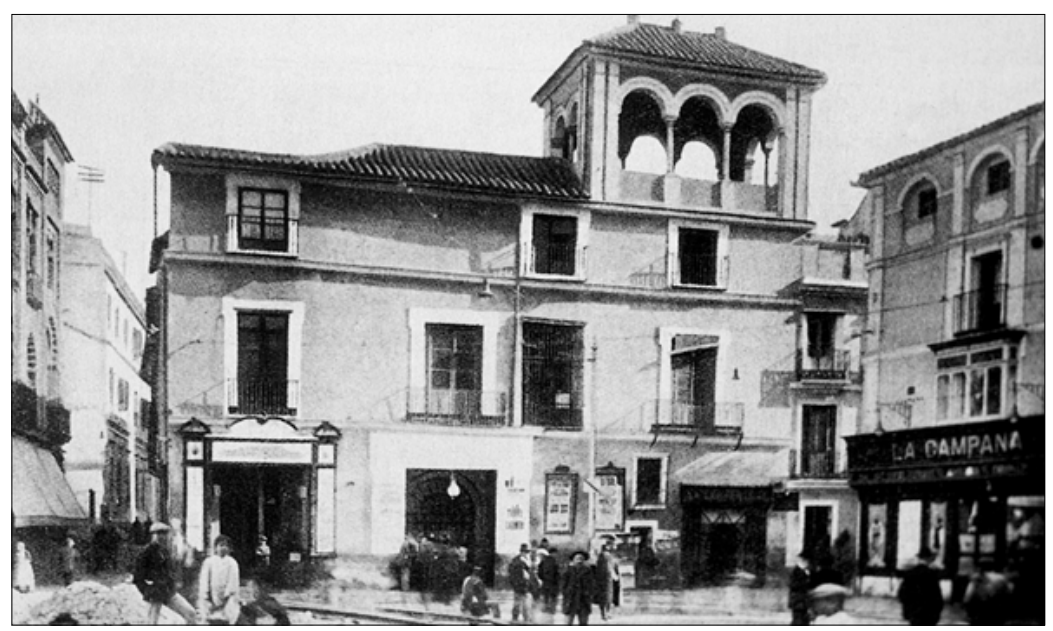

Café Novedades, destruido para el ensanche del entorno de La Campana (Sevilla)
Resulta aún más flagrante la inconveniencia de esta denominación para el caso de las Actividades de Interés Etnológico, cuyos orígenes y evolución histórica en relación con el cambio cultural o tecnológico quedan inadecuadamente aplicados al patrimonio inmaterial. Convendría entonces especificar, en este caso, orígenes de un determinado conocimiento, conexiones entre las "formas de hacer" de determinados saberes con otras de la misma naturaleza, relación del desarrollo de estas actividades con el trazado urbano, la comarcalización, las relaciones y movilidad de los grupos sociales, y otros apartados de este signo. ¿Cuáles son los datos histórico-artísticos de una familia de cantes determinada, de un tipo de baile o una falseta de guitarra?. Se trataría no sólo de presentar la adscripción artística a determinados intérpretes, sino sobre todo rastrear las pistas que la historia nos ofrece sobre cada uno de estos apartados, contrastarlas y elaborar así un recorrido global. Pongamos por caso el nacimiento de la granaína, atribuido a Don Antonio Chacón: se estu- diarían aquí el salto del primitivo "fandango de Graná" a la granaína y la media granaína, las alteraciones melódicas y rítmicas, las transformaciones interpretativas, la aportación de la guitarra, el emparentamiento con las malagueñas y otros cantes derivados del fandango, las recreaciones posteriores de otros intérpretes, etc.

Habría que preguntarse, en este sentido, si el nivel de información posterior sobre descripción y análisis del Planeamiento municipal y territorial -que denota un interés por desarrollar el concepto de patrimonio en el seno de las tensiones derivadas de los procesos de división social del espacio- no debería incorporarse también a la Documentación Técnica de las Actividades de Interés Etnológico, pues muchas de ellas dejan de producirse precisamente por la desaparición de los espacios en los que se asegura su reproducción. Debe aplicarse un concepto conservacionista pero realista del Patrimonio que permita el ajuste de las experiencias tradicionales con los nuevos recursos que ayudan a la mejora en los niveles de vida. La innecesaria y traumática ruptura de un modelo de relaciones, actividades, saberes o prácticas, sin otro objetivo que servir a los beneficios de la inversión privada, no debe consentirse, y cualquier intervención tiene que contar con los intereses y la participación de los actores sociales e instituciones protagonistas.

7. El punto acerca del estado de conservación (sólo para Patrimonio Inmueble) es interesante para algunas expresiones de la Arquitectura Popular como patios, tabernas o pequeños escenarios flamencos, en los que las transformaciones y adaptaciones vividas en los inmuebles funcionan como un texto a través del cual puede leerse la evolución de las formas de vida. Al ser expresión de la cotidianeidad de los pueblos, y a la hora de documentar, resulta difícil sin embargo marcar los límites de una pureza más o menos inerte o estática, por lo que convendría quizá utilizar este epígrafe en el sentido antes propuesto de señalar los principales procesos de transformación vividos y su mayor o menor incidencia en la caracterización patrimonial de los mismos. La Documentación Técnica para una antigua taberna de clara significación flamenca tendrá en cuenta entonces en qué medida los elementos originarios han sufrido cambios de importancia (si es posible, añadiendo la documentación gráfica que se recoge en un punto aparte); qué actividades flamencas que se pueden documentar en tal espacio han desaparecido y cuáles sobreviven; qué grupos, e incluso agentes concretos, podemos identificar en el recorrido más o menos documentable del establecimiento; en qué ha variado el modelo de sociabilidad colectiva que se experimentó entre ellos; y después de todo ello qué tipo de intervención facilitaría su conservación en sentido social y no sólo inmobiliario.

8. Complemento indispensable para cualquier informe técnico, convendría que el apartado de fuentes documentales y bibliográficas incorporara dos aspectos no recogidos. Primero, y habida cuenta de la naturaleza del flamenco como expresión popular, resulta oportunísima la inclusión de información verbal. Gran parte de los datos disponibles para el flamenco parten de 
grupos sociales iletrados o cuyas prácticas no han servido a la atención culta, por lo que no quedan registrados más allá de la memoria y la transmisión oral. De hecho, un notable número de textos flamencos se sustentan en el método biográfico de artistas que nos ofrecen la historia del flamenco del siglo $X X$, a falta de verdadera documentación escrita. Por otro lado, es indispensable ampliar en el flamenco el criterio de "fuente documental" también para la información gráfica y audiovisual ya existente, y no sólo la realizada por el técnico que desarrolla la Documentación. Sobre este particular nos detendremos en un apartado posterior.

9. La situación jurídica es un nivel de información interesante no sólo para el Patrimonio Inmueble, sino también para el Documental y Mueble, ya que el material flamenco se caracteriza por su dispersión en manos de particulares, la existencia de colecciones privadas y, lo más preocupante, por la importante cantidad de material cuyo valor resulta desconocido o menor para sus propietarios o poseedores. Un caso evidente es el de la fotografía flamenca, botón de muestra de tanto material inédito que necesariamente debe abundar en manos privadas y que tal vez no sea reconocido en su justo valor por quienes lo poseen. El expurgo, catalogación de los archivos gráficos de grabados, estampas y series pictóricas de temas flamencos y la construcción de un auténtico archivo gráfico deberían ser objetivos preferentes. Otro tanto sucede con las placas de pizarra, sobre las que ha actuado la Declaración de los Registros Sonoros de la Niña de los Peines como Bien de Interés Cultural. En cualquier caso, intervenciones de estas características pueden tener efectos perversos, debido a las inmediatas repercusiones al alza en el mercado del coleccionismo que dificultan el ejercicio de los derechos de tanteo o retracto y la picaresca en la salida ilícita del material del territorio español. Estudios previos acerca de la situación específica del patrimonio material flamenco se harán indispensables en el futuro como condición inexcusable a las declaraciones o inscripciones de los bienes.

Tal vez por considerar que no existe el mismo concepto de "titularidad" para el patrimonio inmaterial, este apartado no se introduce en las Actividades de Interés Etnológico. Como en otras muestras de cultura popular y folklore, sería aconsejable incorporar alguna anotación sobre los condicionantes jurídicos generales en los que las actividades flamencas desenvuelven, como sucede, de hecho, con la presencia de derechos de autor registrados sobre el material audiovisual flamenco ${ }^{15}$.

10. Finalmente, y respecto a los documentos gráficos, la Documentación Técnica exige registros fotográficos realizados por el documentalista para Bienes Muebles, Inmuebles y Actividades de Interés Etnológico. En el flamenco convendría ampliar el material también para la información sonora y en movimiento, con registros visuales y de sonido, y, sobre todo, hacer acopio del material visual de este signo ya existente, como patrimonio mueble y documental de tipo etnográfico.

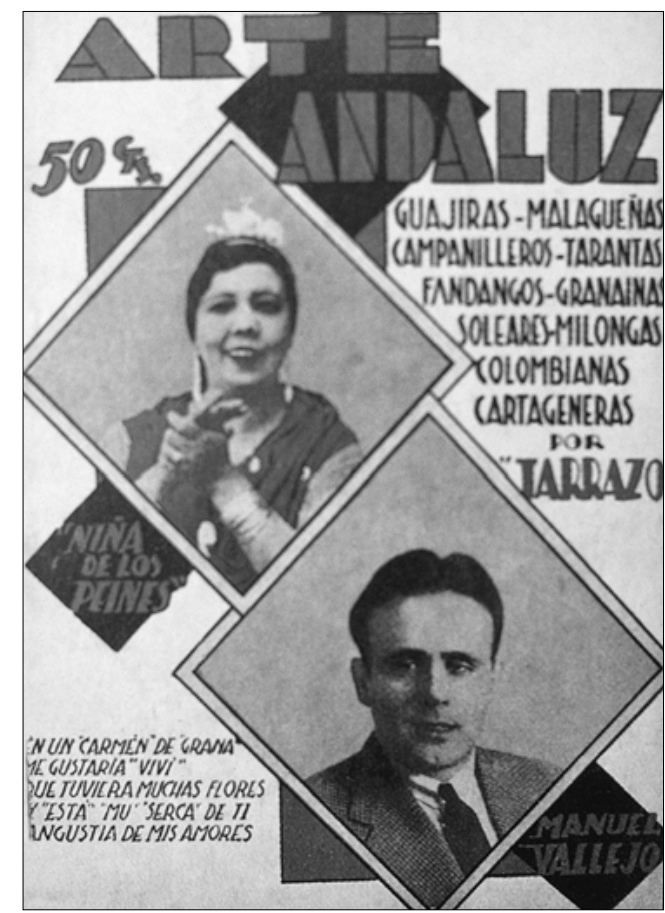

\section{Algunos apuntes sobre la Declaración de BIC de los Registros Sonoros de la Niña de los Peines}

La primera declaración que incluye directamente al flamenco en el repertorio administrativo del Patrimonio Cultural andaluz -la de los Registros Sonoros de la Niña de los Peines- se realiza adoptando la categoría de Patrimonio Documental y la figura de "Bien de Interés Cultural". Esta decisión debe entenderse como un hecho a la vez simbólico y funcional. Más que afrontar una política patrimonial que cubra el conjunto del flamenco como manifestación artística y cultural para lo que posiblemente no existe aún un desarrollo oportuno de los instrumentos legales y administrativos-, se selecciona la producción sonora particular de una figura indiscutida, completísima como artista, receptora y transmisora de estilos múltiples y que transitó por casi todas las etapas del flamenco desde principios de siglo, gracias a su larga carrera como profesional. Un objetivo reconocido en la propia Resolución de Incoación, de hecho, es la puesta en valor de la figura de Pastora como representación personificada del flamenco, por el que se quiere observar "el reconocimiento oficial del sentir popular en una de las facetas culturales más olvidadas por la administración tutelar del Patrimonio Histórico" 16.

Se opta por declarar como bien cultural el conjunto de las placas de pizarra en que Pastora impresionó su voz, esto es, un patrimonio material. En la actualidad se hallan en manos de particulares e instituciones a modo de colección, o bien en número reducido sin propietario localizado. En definitiva, la Administración ha optado por una estrategia continuista: proteccionista para un tipo de patrimonio documental que actualmente se encuentra en desuso y ya forma parte de la historia de los registros sonoros, más que resolver la
Cancionero de la niña de los peines 

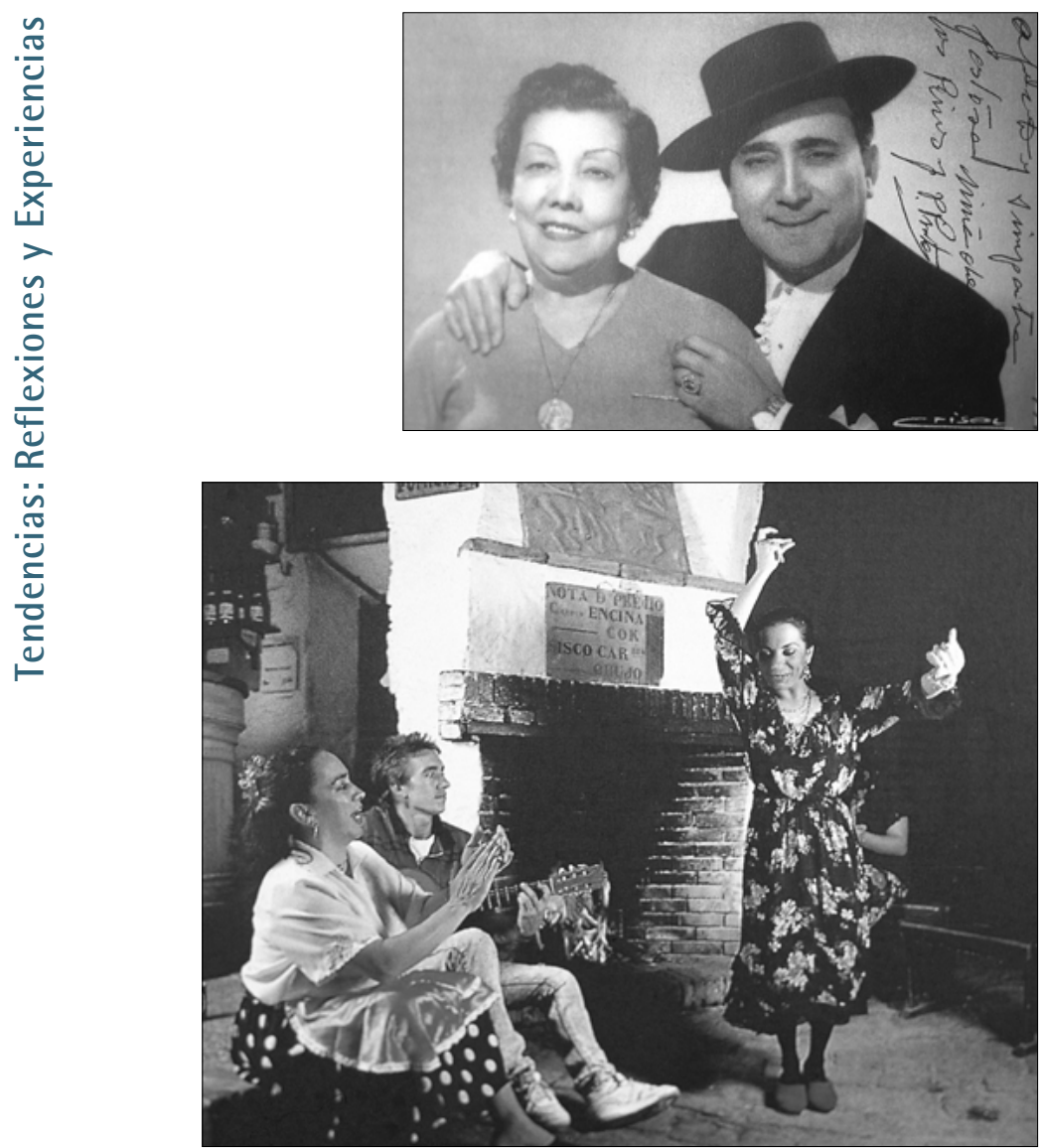

Retrato de Pastora Pavón con su marido Pepe Pinto

Baile flamenco en La Carbonería (Sevilla) incoación del patrimonio flamenco inmaterial o de registros actualizados. Decisión comprensible, teniendo en cuenta lo novedoso de la incorporación del flamenco a la política patrimonial y la necesidad de acometer una estrategia viable.

No se ha elegido para la declaración un elemento que se pueda definir exactamente "en peligro de desaparición", o cuyo valor radique en su rareza, singularidad o escasez. Las placas de pizarra grabadas por Pastora no constituyen piezas exclusivas, únicas o insólitas en el sentido que se le otorga a otros casos. El número de las que se dispone en buen estado es muy abundante, ricas las variedades de cada palo y diversificadas las líneas estilísticas que quedaron registradas y fueron vendidas, por cierto abundantemente. Por otra parte, algunos de los discos de pizarra más antiguos o exitosos fueron reeditados en otras fechas por las casas comerciales, con lo que la compra de placas de Pastora era una tarea relativamente fácil hasta no hace mucho

La preocupación recogida en la resolución de incoación, donde se mencionaba que "La protección de los soportes materiales en que se recoge su voz se hace necesaria en cuanto se encuentran, en muchos casos, en manos de particulares que los están vendiendo fuera del territorio nacional con la consiguiente pérdida de este patrimonio de vital importancia documental", se amparaba más bien en el hecho cierto de que la colección completa no se encontraba disponible en ningún Centro oficial. De ahí que un objetivo declarado en este mismo texto sea "conseguir la protección de los (discos) que se encuentran en manos de particulares, conocidos o desconocidos, sobre los que la Administración Estatal o Autonómica pueda ejercer los derechos de tanteo o retracto o prohibir su salida ilícita del territorio español". El desenlace de esta incoación ha tenido algún efecto contrario a lo perseguido, en tanto no se han podido controlar la dinamización del mercado de compraventa de estas placas y la desmedida elevación de los precios del material disponible.

El procedimiento administrativo para la Declaración de los Registros Sonoros arranca de una denuncia de masiva salida de España de las placas de Pastora, fundamentalmente a Japón 17. Abierto el expediente, el procedimiento comprendió varias fases: I.- Propuesta formulada por el Servicio de Protección del Patrimonio Histórico; 2.- Resolución de Incoación; 3.- Anotación preventiva en el Registro General de Bienes de Interés Cultural; 4.- Comunicación a los propietarios, titulares y poseedores del deber de custodia, mantenimiento y conservación, y del derecho de la Administración a inspeccionar el material; 5.- Cumplimentación de la Documentación Técnica y el informe de los Servicios Técnicos; 6.- Declaración, que afecta a los registros existentes en el territorio andaluz, mediante justificación, exposición del procedimiento, Declaración, incorporación de los registros en el Catálogo General del Patrimonio Histórico, descripción y enumeración de las piezas y advertencia de inclusión de cuantos elementos de la misma naturaleza aparecieran con posterioridad a la declaración.

El pliego para la cumplimentación de la Documentación Técnica disponible por la Administración para el expediente es el extracto reglamentario del Decreto Estatal I I |/1986 de "Patrimonio Documental". Se advierte en su contenido que se trata de un esquema redactado para otro tipo de bienes, bienes singulares sobre todo, muy en la línea que nos hemos encargado de comentar anteriormente ${ }^{18}$. Si la declaración hubiera sido de una pieza única (una bata de cola, una guitarra, un determinado cartel) todos los apartados podrían haber sido recogidos reglamentariamente de forma sencilla. Sin embargo, para los registros sonoros de la Niña de los Peines, determinados contenidos fueron de difícil cumplimentación, debido a la gran cantidad de placas de que se dispone, la indefinición de aspectos tales como los datos histórico-artísticos o el valor económico, la incapacidad de concretar para la totalidad de los discos de pizarra los datos detallados en el punto sobre "situación jurídica", "localización" y "estado de conservación", o de realizar la documentación gráfica de forma individualizada. Sí fue relativamente más fácil ofrecer una descripción general del tipo de soporte material o las referencias al contenido y denominación o título de los registros, que quedaron recogidas en el Anexo a la Declaración final ${ }^{19}$.

Realmente, lo que la Administración buscaba en la Documentación Técnica era más bien una anotación razonada de la significación cultural de esta figura del cante. En el informe -que no reproducimos por lo extenso- no se hace un ejercicio de investigación biográfico puro, ni un estudio en profundidad de la produc- 
ción de Pastora. No es ese el propósito que mueve a este tipo de acciones. Lo que se pretende recoger es una presentación de la cantaora flamenca Pastora Pavón, y sobre todo una recolección lo más fidedigna posible de su obra y un análisis justificativo de su valor singular como emblema del flamenco en su conjunto. Atendiendo a esta necesidad, nuestra Documentación Técnica se dividió en tres apartados:

I. Semblanza biográfica y profesional de la Niña de los Peines.

2. Presentación del carácter y contenido de los registros sonoros con un esquema clasificatorio de los mismos, seguida de un exhaustivo listado de las 184 placas de pizarra que se han documentado, con las guitarras de Ramón Montoya, Luis Molina, Currito de la Jeroma, Niño Ricardo, Manolo de Badajoz, Antonio Moreno y Melchor de Marchena.

3. Reflexión sobre la significación histórica y cultural de Pastora, en base a puntos que la redactora del informe consideró relevantes para el mismo.

Nuestra metodología se ha nutrido sobre todo de técnicas documentales. Por un lado, el análisis de la bibliografía y hemerografía que nos permitiera una reconstrucción biográfica básica. También se ha hecho uso de los propios registros sonoros y del limitadísimo material gráfico en torno a Pastora, fuentes estas últimas "de segunda mano", con lo que hemos alcanzado una revisión y puesta en orden de información dispersa.

El apartado más laborioso en tiempo y esfuerzo, cuyos resultados son un vaciado de información discográfica, ha sido localizar cada una de las placas que integran el compendio ahora protegido. Ha sido necesario un estudio en profundidad de los registros disponibles, la consulta de catálogos aparecidos en diferentes publicaciones y de diversas instituciones ${ }^{20}, y$ la elaboración de un registro final donde se informa de la ubicación exacta de cada una de las placas en las instituciones oficiales. Dichas grabaciones quedan clasificadas en nuestro informe según fecha, guitarrista y casa cantaora. En caso de disponer de la información, se incluye el título del cante, comúnmente por el primer verso o, en el caso de seguiriya y soleá, los primeros versos de las estrofas contenidas en cada corte. Al principio de cada pliego se indica si la numeración corresponde a catálogo, matriz o ambos. Se ha inscrito completa siempre que hemos contado con la información pertinente.
La labor ha sido costosa por varias razones. El etiquetado no siempre contiene las fechas de grabación, y, en algún caso, el cotejo con el catálogo de la casa discográfica no ha sido fructífero. Ante la indeterminación de alguna fecha, se ha optado por no especificar el año de grabación aunque se realice una aproximación estimativa. Hay cantes que aparecen sueltos en alguna distribuidora o son reediciones de impresiones anteriores. Varias casas discográficas desaparecieron, otras se fusionaron, y de alguna sólo tenemos una referencia puntual. En definitiva, un conjunto de escollos que sólo pudimos salvar comparando, uno por uno, los contenidos de las placas que aparecen en los catálogos disponibles -en algunos casos con números diferentes- $y$, a la vista de los errores y las audiciones, deduciendo qué denominación de cante o fecha era la correcta en cada caso.

Estas advertencias se explicitan en el contenido del informe final transmitido a la Dirección General de Bienes Culturales. El apartado más creativo del mismo es, sin duda, el que remite a la significación flamenca de Pastora Pavón, Niña de los Peines. Trata de sintetizar, desde el conocimiento de la historia y la cultura flamencas y andaluzas, los fundamentos que justifican la elección de los registros de Pastora entre otros aspectos patrimoniales del flamenco. Del conocimiento de la historia, la carrera profesional, las cualidades de ejecución, el proceso de aprendizaje y transmisión de su amplio conocimiento flamenco, su repertorio y desarrollo estilístico, concluíamos la multidimensionalidad de la figura, que, por añadidura, simboliza la puesta en valor de dos colectivos habitualmente olividados e invisibles en la redacción de la historia de los "grandes nombres" de la cultura: las mujeres y los gitanos.

Acciones como la que hoy justifican la redacción de este artículo -la declaración de los Registros Sonoros de la Niña de los Peines como Bien de Interés Cultural- son un paso dentro de la necesaria concepción integral del patrimonio flamenco, donde no sólo tienen cabida los soportes materiales discográficos, sino también todos los bienes muebles que rodean las expresiones flamencas andaluzas, así como los lugares de reunión y aprendizaje, el patrimonio literario y el compendio inmaterial de actividades, prácticas, procesos de transmisión, formas de ejecución y sociabilidad. Muestras vivas cuya incoación no está exenta de dificultades de definición, inventariado y sistematización, pero que se hace indispensable detectar para conocer y valorar el flamenco como un marcador identitario sfundamental de nuestra cultura y, por tanto, como patrimonio común de los andaluces. 
I. El Apartado VI referido a tales materiales (desarrollado en el Anexo I.e) del RD I | |/|986), no sólo incluye los bienes materiales, sino también los inmateriales e intangibles, siempre que sean "expresión relevante de la cultura tradicional del pueblo".

2. Ley |/I99|, Título VII, art. 61.

3. Reglamento de Protección y Fomento del Patrimonio Histórico de Andalucía, RD 19/1995, art.3.2.

4. La categoría sin precedente de "Lugar de Interés Etnológico" fue incorporada al Patrimonio Inmueble entre otras cinco, y definida como "parajes naturales, construcciones o instalaciones vinculados a formas de vida, culturas y actividades tradicionales del pueblo andaluz, que merezcan ser preservados por su valor etnológico" (Ley de Patrimonio Histórico de Andalucía, art. 27.6). La de "Actividades de Interés Etnológico" se recoge en el art. 63 de la Ley I/I99/ mediante una tímida definición que incluye prácticas, saberes y otras expresiones culturales.

5. El segundo aspecto fue objeto de desarrollo en profundidad por nuestra parte en "El flamenco y el pueblo. Bases para una política de gestión cultural del flamenco en Andalucía", Actas del XXIV Congreso de Arte Flamenco, Fundación Machado, Sevilla, pp. 27 4I, después reeditado en Candil, $n^{\circ}$ 106, Septiembre-Octubre 1996, pp. 2483-2495. Jaén, y La Caña de Flamenco, Asociación Cultural España Abierta, Madrid, Número 18-19, 1997:27-37.

6. La grandilocuencia, sin más, de la "universalidad del flamenco" nos suena al ansia de introducirlo incondicionalmente en las economías globalizadas del marketing discográfico y las rutas mundiales del espectáculo, sin realizar el oportuno ejercicio de valoración por sus protagonistas. Otra cosa -y en esto no cabe discusión- es afirmar que, partiendo de experiencias particulares e históricamente definidas, las cualidades estéticas, plásticas y hasta de contenido del flamenco (referencias a temas como el amor, la muerte, el destino...) puedan adquirir significación universal.

7. Ley de Patrimonio Histórico de Andalucía, Título VII, art. 6 I ya citado.

8. Título I, art. 3.2 y Anexo I del Reglamento de Protección y Fomento, 1995.

9. Ibidem, Título I, art. 3.4.

10. Se cumpliría así lo estipulado en el art. 86 del Reglamento de Protección y Fomento relativo a "permitir y, en lo posible, fomentar la continuidad de actividades y manifestaciones de interés etnológico". En este último aspecto, el art. 63 de la Ley andaluza de Patrimonio incluye explícitamente las prácticas, saberes y otras expresiones culturales, en especial conocimientos y actividades en peligro de desaparición, como sucede con la práctica del flamenco en lugares tan habituales hasta hace poco como las ferias locales.

I I. Anexo II del Reglamento de Protección y Fomento (RD 19/1995) para la documentación de los expedientes de inscripción: localización del bien patrimonial, denominación, código de identificación, tipología o clasificación, justificación de la inscripción, descripción del bien, delimitación del inmueble (en su caso), bienes muebles vinculados (para inscripción específica de inmuebles), datos histórico-artísticos, estado de conservación, descripción y análisis del planeamiento, fuentes documentales y/o bibliográficas, situación jurídica, observaciones, datos administrativos, documentos gráficos y, para la inscripción específica, instrucciones particulares.

12. Esto es de aplicación al epígrafe de delimitación del inmueble objeto de la inscripción, sobre el que ya no nos detendremos.

13. En el art. 64 de la Ley I//99| se dice: "La inscripción específica en el Catálogo General del Patrimonio Histórico de un Lugar de Interés Etnológico llevará aparejada la necesidad de tener en cuenta los valores que se pretende preservar en el planeamiento urbanístico, adoptando las medidas necesarias para la protección y potenciación de los mismos".

14. El art. 10.1.b) del Reglamento señala, para las actividades, que se incluirá "la relación de aquellos documentos y objetos que se consideren vinculados a las mismas por coadyuvar a su conservación, conocimiento y valoración".
15. Para incorporar esta información se introduce en la Documentación Técnica para la inscripción específica un nivel de "Instrucciones particulares", a modo de resumen de los apartados anteriores, que tiene como objetivo detallar las obligaciones legales generales. De estas Instrucciones Particulares interesa a los bienes etnográficos (el flamenco en particular) la aplicación de la Normativa Urbanística y, para la previa actuación de incoación, la participación de los propietarios y poseedores de los Bienes.

16. Resolución Previa de 9 de junio de 1997, BOJA núm. 232 de 27 de Septiembre de 1997.

17. C. Rioja se encarga de reseñar la regulación de este tipo de procesos a instancias de particulares o "de oficio", y cómo, en el primer caso, la ventaja radica en la implicación común en la conservación del patrimonio, aunque con el inconveniente de entorpecer una política programada y racional de la protección -debido también a los escasos medios humanos- en favor de resolver la "política de urgencia" con que la administración se ve desbordada. Consultar Rioja López, C., "La catalogación del Patrimonio Etnográfico como medio de protección", Patrimonio Etnológico. Nuevas perspectivas de estudio. Instituto Andaluz del Patrimonio Histórico, 1999, pp. 84-94. Junta de Andalucía.

18. ।.- DATOS SOBRE EL BIEN OBJETO DEL EXPEDIENTE: Denominación, Autor (si existe o se conoce), Descripción (tipo de soporte material, fecha, referencia al contenido, características especiales), Datos históricos, Bibliografía, Estado de conservación (condición, partes que faltan, restauraciones realizadas), Localización (Comunidad Autónoma, Provincia, Municipio, Ubicación), Observaciones; II.- SITUACIÓN JURÍDICA: Titular del derecho de propiedad (nombre y apellidos o razón social, domicilio), Poseedor/es (datos personales: nombre y apellidos o razón social, domicilio; título jurídico); III.- DATOS ADMINISTRATIVOS: Expediente $n^{\circ}$, Incoación (fecha de incoación, fecha de notificación de la incoación, fecha de publicación de la incoación en el BOE (cuando se trate de expediente de declaración de Interés Cultural), fecha de comunicación al Registro General de Bienes de Interés Cultural o al Inventario General), Instrucción (instrucciones consultivas que han emitido informe favorable (cuando se trate de expediente de declaración de Bien de Interés Cultural), fecha de la notificación del acuerdo de la Comunidad Autónoma a los interesados sobre procedencia de la declaración o de la inclusión), Recursos presentados contra actos del expediente, Valor económico (en el caso de que se declare conforme a la Disposición Transitoria Primera de este Real Decreto); IV.DOCUMENTOS GRÁFICOS: Dos fotografías en color del tamaño $8 \times 12 \mathrm{cms}$. (una de conjunto y otra de un detalle característico si el objeto lo requiere para su identificación o en su caso, del anverso y del reverso) y los correspondientes negativos.

19. Se puede consultar en el Decreto I35/1999 de 25 de mayo, BOJA núm. 76 de 3 de julio de 1999 y BOE |9| de II de agosto de 1999

20. Centro Andaluz de Flamenco, Centro de Documentación Musical de Andalucía, Diputación Provincial de Sevilla, Biblioteca Nacional, colecciones privadas, catálogos de casas comerciales, y fuentes como el Diccionario Enciclopédico llustrado del Flamenco, de José Blas Vega y Manuel Ríos Ruiz (Editorial Cinterco, Madrid, 1988) o Antonio Mairena en el mundo de la siguiriya y la Soleá, redactado por Luis Soler Guevara y Ramón Soler Díaz (Fundación Antonio Mairena, Málaga, 1992), donde se puede encontrar la discografía de Pastora por soleá y seguiriya. En ninguna de estas fuentes aparece el compendio completo de las grabaciones de Pastora Pavón, de las que no se dispone en ningún caso, y se puede afirmar que no existe en ninguna de ellas una clasificación exhaustiva de los cantes. Los listados se limitan a recoger los fondos disponibles para cada institución o colección privada. Aparte de los existentes en centros administrativos y de documentación consultados, correctamente custodiados, existe una lamentable dispersión de los registros sonoros, básicamente en manos de particulares y colecciones no catalogadas. 